\title{
Obesity in adult Nigerians: a study of its prevalence and common primary co-morbidities in a semi-urban Mission General Hospital in South-Eastern Nigeria.
}

\author{
${ }^{*}$ Iloh GUP MBBS, MPH, FMCFM, FWACP(FM), MPA, ${ }^{* *}$ Amadi AN B.Sc,M.Sc,Ph.D, **Nwankwo BO B.Sc, MPH, Ph.D. \\ *Department of Family Medicine, Federal Medical Centre, Umuahia, Abia state, Nigeria and visiting Consultant \\ Family Physician, St. Damian's Hospital, Okporo, Orlu, Imo state, Nigeria **Department of Public Health \\ Technology, Federal University of Technology, Owerri, Imo state, Nigeria
}

\begin{abstract}
Background: Obesity is socially and culturally acceptable in Nigeria and therefore not usually recognized as a medical problem. This study is aimed at determining the prevalence of obesity using body mass index(BMI) criterion and its common primary comorbidities among adult Nigerians attending a semiurban Mission General Hospital in Imo state, SouthEastern, Nigeria.
\end{abstract}

Methods: A descriptive study using primary data collection technique was carried out from October 2007 to December 2008. A total of 9296 consecutive new adult patients aged 18-88 years were screened for obesity using BMI criterion and 684 patients who had $B M l=30 \mathrm{~kg} / \mathrm{m}^{2}$ met the inclusion criteria. The data collected included age, sex, marital status, education, occupation, weight(kilogram), height(meters), and blood pressure; fasting blood sugar and fasting lipid profile. Obese patients' perception of their obese condition and knowledge of lifestyle modification were also assessed.

Results: Six hundred and eighty-four(7.4\%) out of a total of 9296 patients screened for obesity were obese. Hypertension(18.4\%) was the commonest primary comorbidity, others include high triglyceridaemia(9.2\%), high total cholesterol(8.2\%), high LDLcholesterol(6.0\%) and diabetes mellitus(3.4\%). One hundred and one(14.8\%) obese patients were aware of their obese condition and majority, 72(71.3\%) of them were informed of their obese condition by healthcare professionals. Forty seven(46.5\%) of those who were aware of their obese condition had knowledge of lifestyle modification. However, majority (72.3\%) of those who had knowledge of lifestyle modification demonstrated low knowledge level of lifestyle modification.

Conclusion: This study has shown the existence of obesity and its common primary co-morbidities among the study population. Anthropometric determination of obesity and screening for its common primary co- morbidities should be integrated as part of clinic baseline assessment of adult Nigerians attending semiurban hospitals. Those who had obesity-related primary co morbidities should become secondary target for risk reduction therapy and appropriate management.

Key words: Adult, Obesity, Prevalence, Comorbidities, Semi-urban, Hospital, Nigeria.

\section{Date Accepted for Publication: $11^{\text {th }}$ October 2009 \\ NigerJMed 2010: 459 - 466 \\ Copyright@2010 Nigerian Journal of Medicine}

\section{Introduction}

Obesity is generally regarded as a pandemic with potentially disastrous consequences for human health". Obesity generally results from a chronic imbalance between energy intake and expenditure ${ }^{2}$. It is defined as an excess of adipose tissues resulting in body mass index $(\mathrm{BMI})=30 \mathrm{~kg} / \mathrm{m}^{2}$. The body mass index(Quatelet index) is calculated by dividing measured body weight in kilogram by the square of the height in metres. The National Institute of Health(NIH) defines normal weight as $\mathrm{BMI}(18.5-24.9)$, overweight(BMI:25-29.9), class I obesity(BMI:30-34.9), class II obesity(BMI:35-39-9), class III obesity(BMI:=40) ${ }^{3}$. Until recently, obesity was considered the direct result of two weight-linked behaviours of physical inactivity and chronic ingestion of excess calories ${ }^{2}$. Although these factors are undoubtedly the principal cause in some cases, there is now strong evidence of genetic influence ${ }^{2,4}$. However, most human obesity generally develops from the interactions of multiple genes, environmental and behavioural factors ${ }^{2}$.

Obesity once thought the health problem of affluent Western World now has increased in prevalence in many developing countries ${ }^{5}$, and has been described as a time bomb for the future explosion in the frequency of cardiovascular diseases, type II diabetes mellitus and dyslipidaemia ${ }^{6}$. As developing countries continue to combat communicable diseases such as HIVIAIDS, 
tuberculosis leading to longer life expectancies, there is also emerging an unprecedented epidemic of obesity and its primary co-morbidies ${ }^{6}$. It has been suggested that obesity can be used to identify without clinical diagnosis those who are mostly at risk of several chronic non-communicable diseases ${ }^{7,8}$.

The potential health hazards of obesity have been documented extensively particularly in relation to its common primary co-morbidities such as cardiovascular diseases, type II diabetes mellitus and dyslipidaemia $a^{5,9}$. The presence of health risk of obesity is related to the location of excess fat, duration and degree of obesity. However, medical risk of obesity is highly associated with the distribution of the body fat and abdominal fat is considered at least as important a medical risk as the total amount of body fat ${ }^{1}$. The National Health And Nutritional Examination Surveys(NHANES) have shown that increase in BMI is usually associated with increase in the prevalence of type II diabetes mellitus, hypertension and dyslipidaemia ${ }^{10}$. The body mass index therefore provides guidelines on the identification, evaluation and treatment of adults who are obese ${ }^{9}$. According to the American Heart Association(AHA), obesity is a major independent risk factor for coronary heart disease and appears to interact with or amplify the effects of other cardiovascular risk factors including hypertension, diabetes mellitus and dyslipidaemia ${ }^{11}$.

Globally, rising trends in morbidity and mortality related to chronic non-communicable diseases have led the World Health Organization(WHO) and other international and national organizations to device strategies for chronic non-communicable disease prevention and control $^{8,12}$. In the recent years, developing nations including Nigeria have started responding to the rise in the prevalence of obesity and obesity-related diseases ${ }^{8,12}$. The principal aim is to identify mutable and immutable risk factors involved in these medical conditions; and to formulate a suitable programme for early detection and effective control.

In our families, urban, semi-urban and rural communities, developing and developed nations, people die each year from medical consequences of obesity despite its largely modifiable risk factors. Since developing countries have fewer resources to manage obesity and its co-morbidities than developed countries, it is therefore important to identify interventions that are effective, inexpensive, widely practicable and culturally acceptable.
In Nigeria, obese patients frequently present to the General Medical Practitioners. The early recognition of obesity by clinicians is quintessential to its management whilst identifying its common primary co-morbidities avails great opportunities for prevention and control. General Hospitals in semi-urban communities are usually the first port of call for these patients in Nigeria. This study is aimed at determining the prevalence of obesity and its common primary co-morbidities in adult Nigerians in a semi-urban Mission General Hospital in Imo state, South-Eastern Nigeria. This General Hospital setting provides first contact hospital services to the community and its environs and may give a better picture of the burden of obesity and its common primary co-morbidities in the study area.

\section{Materials and Methods}

This was a clinic-based descriptive study using primary data collection technique carried out from October 2007 to December 2008. A total of 9296 consecutive new adult patients aged 18-88 years were screened for obesity using BMI criterion and 684 patients with BMI $=30 \mathrm{~kg} / \mathrm{m}^{2}$ who consented to participate in the study were recruited at the General Outpatient Clinic of St. Damian's Hospital, Okporo, a Catholic Hospital in Orlu, Imo state, South-Eastern Nigeria. The 18 years and above cut off was in tandem with seventh report of the Joint National Committee on prevention, detection, evaluation and treatment of high blood pressure in adults aged 18 years and older ${ }^{13}$. Critically ill patients, pregnant women, patients who had ascites and other forms of oedema and patients who had physical deformities affecting the spine and/or the limbs and could not stand for height and weight measurement were excluded from the study. Sample size estimation was determined using the formula ${ }^{14}$ for estimating minimum sample size for descriptive studies when studying proportions with entire population of $<10,000$ using estimated population size of 9000 adult patients based on the previous annual adult patients population clinic attendance of the hospital. The estimated minimum sample size using prevalence of obesity of $16.3 \%$ from previous study gave a final sample size estimate of 203 patients. However, selected sample size of 684 adult patients was used based on proposed duration of the study. The clinic runs during working hours from Monday to Friday including public holidays. The data collected included age, sex, marital status, education and occupation; weight $(\mathrm{kg})$, height $\left(\mathrm{m}^{2}\right)$ and blood pressure; fasting blood sugar and fasting lipid profile(total cholesterol, triglycerides, high density lipoproteins(HDL) cholesterol and low density 
lipoproteins(LDL)cholesterol. The social classification of patients was based on five point occupational scale used byAbramson ${ }^{15}$.

This study also assessed the awareness(perception) of their obese condition, sources of awareness of information on their obese condition and knowledge of lifestyle modification. On further assessment of their knowledge of lifestyle modification for obesity, appropriate questions were asked with the coding of the responses indicating high, moderate, low knowledge levels of lifestyle modification.

The weight was measured in kilograms with patients standing bare feet in their minimal clothing and with their pockets free of objects that might add to their weights such as mobile phones, wallets, keys, rings etc using a bathroom weighing scale(Hamson, China) which was validated daily using a known $10 \mathrm{~kg}$ weighted mass and measured to the nearest $0.1 \mathrm{~kg}$. The weighing scale was checked for zero error after each measurement. Height was obtained in metres using a standard stadiometer. In measuring the height, the patient who was barefooted and without head-gear or cap stood against the stadiometer with the Achilles, gluteus and occiput touching it. A pointer was pressed firmly against the scalp and the measurement read off in meters. The body mass index $=30 \mathrm{~kg} / \mathrm{m}^{2}$ was taken as the operational definition of obesity with the following categorization ${ }^{3}$ : class I obesity=body mass index of 30 34.9 , class II obesity=body mass index of 35-39.9 and class III obesity=body mass index of $=40$.

The blood pressure was measured using auscultatory method with standard mercury in glass Accuson sphygmomanometer. Prior to the measurement, the patient was seated and rested for 5 minutes ${ }^{16}$ in sitting position on a chair that supported the back comfortably. The left arm muscles were relaxed and the forearm was supported with the cubital fossa at the heart level. A cuff of suitable size was applied evenly to the exposed arm. The cuff was rapidly inflated until the manometer reading was about $30 \mathrm{mmHg}$ above the level at which the pulse disappeared and then slowly deflected. During this time, the Korotkoff sounds were monitored using a Litman stethoscope placed over the brachial artery. The systolic blood pressure was noted at the pressure at which the first heart sounds were heard(Korotkoff phase I). The diastolic blood pressure was taken as the pressure at the point when the heart sounds disappeared(Korotkoff phase v). The blood pressure was also measured in the right arm as described for the left arm and the arm that gave the higher reading was subsequently used ${ }^{16}$. The systolic and diastolic blood pressures were measured twice separated by an interval of 2 minutes $^{16}$. The three readings were recorded and the mean value was calculated. Hypertension is defined as systolic and/or diastolic blood pressures(BP) $=140 / 90 \mathrm{mmHg}$ in tandem with the seventh report of the Joint National Committee on prevention, detection, evaluation and treatment of high blood pressure in adult aged 18 years and older ${ }^{13}$.

Diabetes mellitus was defined by venous plasma fasting blood sugar=126 $\mathrm{mg} / \mathrm{dl}(7.0 \mathrm{mmol} / \mathrm{l})$ after an overnight fast which was confirmed by a repeat test on the second clinic visit ${ }^{17}$. Dyslipidaemia(atherogenic lipid profile) is defined operationally as serum triglyceride $=150 \mathrm{mg} / \mathrm{dl}(1.7 \mathrm{mmol} / \mathrm{l}) ;$ low density lipoprotein cholesterol $=100 \mathrm{mg} / \mathrm{dl}(2.58 \mathrm{mmol} / \mathrm{l})$; high density lipoprotein cholesterol $=40 \mathrm{mg} / \mathrm{dl}(1.03 \mathrm{mmol} /)^{18}$.

Statistics: The results generated were analysed using software SPSS version 13.0, Chicago for the calculation of mean, frequencies and percentages.

\section{Results}

Six hundred and eighty four (7.4\%) out of a total of 9296 consecutive new adult patients screened were obese(i.e, had $\mathrm{BMl}=30 \mathrm{~kg} / \mathrm{m}^{2}$ ), with $566(82.8 \%$ ) having class I obesity(i.e., BMI:30-34.9), 107(15.6\%) had class II obesity(i.e. BMI:35-39.9) and 11(1.6\%) had class III obesity(i.e., BMl:=40)(Table I).

The age of the obese patients ranged from 18 to 88 years with mean age of $48.80 \pm 14.60$ years. Majority of the obese patients were young adults(1839 years) $(46.2 \%)$ followed by the middle aged adults (40-64years) $(39.6 \%)$ and the elderly(=65years) $(14.2 \%)$. There were $203(29.7 \%)$ males and $481(70.3 \%)$ females with male to female ratio of 1:2.4. The true sex prevalence of obesity among the 9296 consecutive new adult patients screened was $2.2 \%$ and $5.2 \%$ for male and female respectively. Majority of the obese patients were married $(62.7 \%)$, had primary education(49.0\%), farmers(36.1\%) and petty traders $(26.0 \%)$ and belonged to social classes III(45.9\%) and V(34.4\%)(Table II).

One hundred and twenty six $(18.4 \%)$ of the obese patients were hypertensive $(\mathrm{BP}=140 / 90 \mathrm{mmHg})$, one hundred and eighty-two(26.6\%) were normotensive, three hundred and seventy-six $(55.0 \%)$ were prehypertensive, eighty-nine $(13.0 \%)$ had stage I hypertension and thirty-seven had stage II hypertension(5.4\%)(Table III). 
Twenty three(3.4\%) of the obese patients were diabetic while $661(96.6 \%)$ were euglycaemic.(Table III). The lipid profile showed that $56(8.2 \%)$ had raised total cholesterol $=200 \mathrm{mg} / \mathrm{dl}, 63(9.2 \%)$ had raised triglyceride $=150 \mathrm{mg} / \mathrm{dl}, 41(6.0 \%)$ had raised LDL cholesterol and $560(81.9 \%)$ had low HDL cholesterol(Table lil).

On the assessment of the awareness of their obese condition, only $101(14.8 \%)$ admitted they were aware of their obese condition while 583(85.2\%) were not aware of their obese condition(Table IV). Majority $72(71.3 \%)$ of those who were aware of their obese condition were informed of their obese condition by healthcare professionals(Table V). On the knowledge of lifestyle modification for those who were aware of their obese condition, $47(46.5 \%)$ had knowledge of lifestyle modification while $54(53.5 \%)$ had no knowledge of any form of lifestyle modification(Table $\mathrm{VI})$. On further assessment of their level of knowledge of lifestyle modification for obesity, majority, 34(72.3\%) of those who had knowledge of lifestyle modification exhibited low level of knowledge, 9(19.2\%) showed moderate knowledge level while 4(8.5\%) demonstrated high knowledge level of lifestyle modification(Table VII).

\begin{tabular}{|c|c|}
\hline \multicolumn{2}{|l|}{ Prevalence } \\
\hline Status & Number(\%) \\
\hline BMle $30 \mathrm{~kg} / \mathrm{m}^{2}$ & $684(7.4 \%)$ \\
\hline BMI $<30 \mathrm{~kg} / \mathrm{m}^{2}$ & $8612(92.6 \%)$ \\
\hline Total & $9296(100.0 \%)$ \\
\hline \multicolumn{2}{|l|}{ BMI e30 $\mathrm{kg} / \mathrm{m}^{2}$ categories } \\
\hline Class I obesity(BMI:30-34.9) & $566(82.8 \%)$ \\
\hline Class II obesity(BMI:35-39.9) & $107(15.6 \%)$ \\
\hline Class III obesity(BMI:e40) & $11(1.6 \%)$ \\
\hline Total & $684(100.0 \%)$ \\
\hline
\end{tabular}

\begin{tabular}{|c|c|}
\hline Parameter & Number $(\%)$ \\
\hline \multicolumn{2}{|l|}{ Age(years) } \\
\hline $18-39$ & $316(46.2 \%)$ \\
\hline $40-64$ & $271(39.6 \%)$ \\
\hline e65 & $97(14.2 \%)$ \\
\hline Total & $684(100.0 \%)$ \\
\hline \multicolumn{2}{|l|}{ Gender } \\
\hline Male & $203(29.7 \%)$ \\
\hline Female & $481(70.3 \%)$ \\
\hline Total & $684(100.0 \%)$ \\
\hline \multicolumn{2}{|l|}{ Marital status } \\
\hline Single & $187(27.3 \%)$ \\
\hline Married & $429(62.7 \%)$ \\
\hline Widowed & $56(8.2 \%)$ \\
\hline Separated/divorced & $12(1.8 \%)$ \\
\hline Total & $684(100.0 \%)$ \\
\hline
\end{tabular}

$\begin{array}{lc}\text { Education } & \\ \text { No formal education } & 11(1.6 \%) \\ \text { Primary } & 335(49.0 \%) \\ \text { Secondary } & 289(42.2 \%) \\ \text { Post-secondary } & 49(7.2 \%) \\ \text { Total } & 684(100.0 \%) \\ \text { Occupation } & \\ \text { Unemployed } & 11(1.6 \%) \\ \text { Student/apprentice } & 16(2.3 \%) \\ \text { Public/civil servants } & 55(8.0 \%) \\ \text { Farming } & 247(36.1 \%) \\ \text { Trading } & 178(26.0 \%) \\ \text { Driving } & 77(11.3 \%) \\ \text { Artisans } & 96(14.1 \%) \\ \text { Business executive/professionals } & 4(0.6 \%) \\ \text { Total } & 684(100.0 \%) \\ \text { Social class } & \\ \text { Class I } & 2(0.3 \%) \\ \text { Class II } & 41(6.0 \%) \\ \text { Class III } & 314(45.9 \%) \\ \text { Class IV } & 92(13.4 \%) \\ \text { Class V } & 235(34.4 \%) \\ \text { Total } & 684(100.0 \%) \\ \end{array}$

Table III: Primary co-morbidities of the obese patients

$\begin{array}{lcc}\text { Parameter } & & \text { Number(\%) } \\ \text { Hypertension(SBP/DBPe140/90 mmHg) } & \text { Yes } & 126(18.4 \%) \\ & \text { No } & 558(81.6 \%) \\ & \text { Total } & 684(100.0 \%) \\ \text { Blood Pressure categories } & & \\ \text { Normal } & 182(26.6 \%) \\ \text { Pre-hypertension } & 376(55.0 \%) \\ \text { Stage I hypertension } & 89(13.0 \%) \\ \text { Stage II hypertension } & 37(5.4 \%) \\ \text { Total } & & 684(100.0 \%) \\ \text { Fasting Blood Sugar(plasma) } & \\ <126 \text { mg/dl(euglycaemia) } & 661(96.6 \%) \\ \text { Diabetes mellitus } & 23(3.4 \%) \\ \text { Total } & 684(100.0 \%) \\ \text { Lipid profile } & \\ \text { Total cholesterol } & \\ <200 \text { mg/dl } & 684(100.0 \%) \\ \text { e200 mg/dl } & \end{array}$




$\begin{array}{lc}\text { Triglyceride } & \\ <150 \mathrm{mg} / \mathrm{dl} & 621(90.8 \%) \\ \text { e150 mg/dl } & 63(9.2 \%) \\ \text { Total } & 684(100.0 \%) \\ \text { Low density lipoprotein cholesterol } & \\ <100 \mathrm{mg} / \mathrm{dl} & 643(94.0 \%) \\ \text { e100 mg/dl } & 41(6.0 \%) \\ \text { Total } & 684(100.0 \%) \\ \text { High density lipoprotein cholesterol } & \\ <40 \mathrm{mg} / \mathrm{dl} & 560(81.9 \%) \\ \text { e40 mg/dl } & 124(18.1 \%) \\ \text { Total } & 684(100.0 \%)\end{array}$

Table IV: Patients awareness of their obese condition( $N=684)$

\begin{tabular}{lc}
\hline Status & Number(\%) \\
Aware & $101(14.8 \%)$ \\
Not aware & $583(85.2 \%)$ \\
Total & $684(100.0 \%)$ \\
\hline
\end{tabular}

Table V: Main source of awareness of information about their obese condition( $\mathrm{N}=101)$

$\begin{array}{lc}\text { Source(main) } & \text { Number(\%) } \\ \text { Self } & 15(14.9 \%) \\ \text { Friends/peers } & 8(7.9 \%) \\ \text { Relatives } & 6(5.9 \%) \\ \text { Health professionals } & 72(71.3 \%) \\ \text { Total } & 101(100.0 \%)\end{array}$

Table Vl: Knowledge of lifestyle modification among obese patients( $\mathrm{N}=101)$

\begin{tabular}{lc}
\hline Status & Number(\%) \\
Knowledge of lifestyle modifications & $47(46.5 \%)$ \\
No knowledge of lifestyle modifications & $54(53.5 \%)$ \\
Total & $101(100.0 \%)$
\end{tabular}

Table VII: Distribution of the obese patients who had knowledge of lifestyle modifications based on their knowledge level( $\mathrm{N}=47)$

\begin{tabular}{lc}
\hline Knowledge level & Number(\%) \\
High & $4(8.5 \%)$ \\
Moderate & $9(19.2 \%)$ \\
Low & $34(72.3 \%)$ \\
Total & $47(100.0 \%)$ \\
\hline
\end{tabular}

\section{Discussion}

The prevalence of obesity has increased within the last two decades and continues to rise in both developed and developing countries ${ }^{6}$. The prevalence rate of obesity $(7.4 \%)$ in this study is higher than that reported from urban area of $\operatorname{Jos}(6.4 \%)^{19}$ and rural area of Maiduguri $(2 \%)^{20}$. However, the prevalence of obesity in this study is lower than that reported from urban(Port Harcourt $=14.0 \%$ ) and rural(Okrika $=16.3 \%$ ) areas of Rivers state $^{21}$, llorin(13.2\%) $)^{23}$, and in other countries such as urban and rural Cameroon(17.1\% $)^{22}$. These reports buttress the fact that obesity is still an issue of serious medical importance globally, presently occurring at epidemic proportions in developed nations ${ }^{6}$ and also escalating in Nigeria as an important component of non-communicable disease burden in rural, semi-urban and urban areas of the country ${ }^{5,12,19-21}$. This report and other reports from developing nations have buttress the observation that the prevalence rates of obesity in developing countries are relatively low but are changing rapidly with urban and rural variations ${ }^{8}$. However, the prevalence of obesity has been reported to be higher in urban than rural communities ${ }^{6-8,87}$. This urban-rural variation is attributed to the observation that urban population is usually associated with modernization of lifestyle which is largely characterized by change in dietary pattern and lower physical activity including personal, instrumental and domestic activities of daily living when compared with rural population.

The finding in this study of higher prevalence of obesity among young and middle-aged adult patients is similar to the reports from $\mathrm{Jos}^{19}$, Maiduguri ${ }^{20}$, and Rivers state $^{21}$. According to these reports, prevalence of obesity as defined by body mass index parameter increases with age ${ }^{5,21}$. However, it has also been reported that anthropometric determination of obesity using body mass index criterion could be a less valid indicator of obesity among the elderly who tend to have a shift of fat from peripheral to central sites ${ }^{21}$. For such population, waist circumference, a measure of central obesity is preferred ${ }^{21,23}$. More so, obesity increases with age as physical activities diminish and central obesity arises as peripheral fat is diverted to central sites.

This study observed higher prevalence of obesity among females $(5.2 \%)$ compared to males( $2.2 \%)$. This finding is similar to previous reports from Maiduguri ${ }^{20}$, Rivers state ${ }^{21}$, and Cameroon ${ }^{22}$. Other studies have reported higher prevalence of obesity among female gender $^{5,24}$. The higher prevalence of obesity among the female gender may be attributed to the generalization that females are less physically active than males ${ }^{25}$. However, apart from changes in the energy density of diets and physical inactivity, genetic differences between the sexes may be contributory ${ }^{2,23}$.

Hypertension was the commonest primary co-morbidity among the obese patients. The prevalence rate of hypertension in this study is similar to the reports from Maiduguri $(15.2 \%)^{20}$ and Edo state(Udo)(20.2\%) $)^{32}$. The prevalence of hypertension of $18.4 \%$ in this study is higher than the prevalence rate of $10-15 \%$ reported in 
the Nigerian national survey ${ }^{27}$ but lower than the extrapolated prevalence rate of $20 \%$ from the 1997 nationwide survey of non-communicable diseases in Nigeria. The finding in this study may be a reflection of the burden of hypertension among the study population and corroborates the report that prevalence of hypertension is on the rise in Nigeria ${ }^{12,26,27}$. According to these reports from Nigeria, hypertension is the commonest non-communicable disease in Nigeria ${ }^{12,26-28}$. More so hypertension has become a public health problem worldwide especially in sub-Saharan Africa where it is increasing in importance as a component of non-communicable disease burden and a major cause of cardiovascular morbidity and mortality.

The prevalence of diabetes mellitus of $3.4 \%$ in this study is within the prevalence rates of $2-4 \%$ reported in Nigeria by Akinkugbe ${ }^{12,27}$. However, this finding is higher than the prevalence rates reported in Maiduguri $(3.0 \%)^{20}$, Zaria(2.0\% $)^{29}$ and lower than the prevalence rates reported in Port Harcourt $(6.8 \%)^{21}$. Our finding is in keeping with the reports that prevalence of diabetes mellitus depends on the population group under study with rural, semi-urban and urban variations $\mathrm{s}^{30}$ and has reportedly increased over the past two decades in both developing countries such as Nigeria ${ }^{5}$ and developed countries such as United States of America ${ }^{31}$. This increase is presumed to be due to diet style, population aging, physical inactivity and increasing prevalence of obesity.

The prevalence and pattern of dyslipidaemia in this study is similar to the pattern described in previous studies ${ }^{32,33}$. According to these reports, dyslipidaemia is associated with obesity in the umbrella term called metabolic syndrome ${ }^{18,32}$. However, the prevalence of dyslipidaemia in these reports varies with its operational definitions among the study population .

The finding of low awareness(14.8\%) and perception of obese condition among the study population gave credence to the observation that obesity is socially and culturally acceptable among Nigerians as an indication of good health and affluence and is therefore not usually regarded as a pathological condition. This leads to missed opportunities to screen and counsel patients on obesity and its co-morbidities. This perception needs a lot of awareness and knowledge to understand it as a pathological condition that can be reduced through lifestyle changes involving healthy diet and adequate $\operatorname{diet}^{34,35}$.
Study implications: This study has substantial implications for clinical practice and public health especially in this era of epidemiologic and demographic transition in Nigeria $^{28}$. It underscores the need for health promotion, risk reduction, health education and counselling as well as medical decision making such as screening protocols for diseases of lifestyle such as obesity, hypertension, diabetes mellitus and dyslipidaemia. The study highlights the benefits of promoting the culture of normal weight, healthy diet, adequate physical activity and appropriate management of obesity and obesity-related primary comorbidities. This study therefore provides useful baseline information on which subsequent interventions in the study area could be based and assessed.

Study limitations: The researchers had certain constraints which imposed some degree of limitations to the absolute generalization of the findings: The unreliability of height measurements make BMI a fairly accurate index of obesity especially in older persons ${ }^{36}$. Although, the ideal measurement of obesity should consider both the amount and site of deposition of the adipose tissues, the waist indices(waist circumference, waist-hip ratio, Rohrer's index, Ponderal index) were not used for the definition of obesity in this study. However, many studies and literature reviews have documented a strong correlation between Quatelet Index and waist circumference and that Quatelet index provides a simple clinical estimate of generalized adiposity that can be compared across studies and populations ${ }^{23,36}$. This is supported by its significant associations with obesity-related risk factors such as dyslipidaemia, dysglycaemia and hypertension ${ }^{36}$. More so, waist circumference measures regional adiposity( amount of fat in the abdomen) ${ }^{3}$.

Conclusion: Obesity and its primary co-morbidities exist among the study population and constitute an important health problem. These primary obesityrelated co-morbidities may invariably predispose them to increase cardiovascular morbidity, mortality and all cause mortality. The study also underscores the importance of clinicians making a diagnosis of obesity and its common primary co-morbidities and most importantly counselling patients appropriately on lifestyle modifications. It is recommended that anthropometric determination of obesity and screening for its common primary co-morbidities be integrated as part of clinic baseline assessment of adult Nigerians attending semi-urban hospitals to facilitate their early detection and institutionalization of appropriate preventive and therapeutic measures. Long-term 
targeted primary prevention intervention programmes on obesity should be instituted in the General Hospitals whilst patients who had obesity-related primary comorbidities should constitute secondary target for risk reduction therapy and appropriate management.

\section{References}

1. Finer N. Obesity. Clinical Medicine 2003; 3(1): 23-27.

2. Baron RB. Nutritional Disorders. In Mcphee SJ, Papadakis MA, Tierney LM eds. Current Medical Diagnosis and Treatment, $46^{\text {th }}$ edn., New York. Lange Medical Books 2007;1290-1296.

3. Clinical Guidelines on the Identification, Evaluation and Treatment of Overweight and Obesity in Adults: the evidence report. Bethesda, Md.: National Institutes of Health, National Heart, Lung and Blood Institute, 1998. NIH publication no.984083.

4. Mantzoros CS. The role of leptin in human obesity and disease: a review of current evidence. Ann Intern Med 1999; 130:671.

5. Abidoye RO, Izunwa RD, Akinkuade FO, Abidoye GO. Interrelationships between lifestyle and diabetes mellitus, overweight, obesity and hypertension in Nigeria. Nutr Health 2003; 16(3):203-213.

6. Bray GA. Obesity: a time bomb to be defused. Lancet 1998; 18:160-161.

7. WHO. Prevention and management of the global epidemic of obesity. Report of the WHO Consultation in obesity. Geneva, 3-5 June 1997(WHO/NUT/NCD/98.1).

8. WHO. Global strategy on diet, physical activity and health. Bulletins of the WHO 2006; 5:16-18.

9. National Task Force on the Prevention and Treatment of Obesity, Overweight and Health Risk. Arch Intern Med 2000; 160:898-904.

10. Bays HE, Chapman RH, Grandy S. The relationships of body mass index to diabetes mellitus, hypertension and dyslipidaemia. Comparison of data from two national surveys. International Journal of Clinical Practice 2007; 61(5): 737-747.

11. Eckel RH, Krauss RM. American Heart Association call to action: obesity as a major risk factor for coronary heart disease. AHA Nutrition Committee. Circulation 1998; 97:2099-2100.

12. Akinkugbe OO. Non-communicable diseases in Nigeria, The next epidemics: Nigeria preparedness. Third Biennial Abayomi Bamidele Memorial Lectures. Nigerian Journal of Clinical Pactice 2000; 3:37-42.

13. Chobanian AV, Bakris GL, Black HR, Cushman WC, Green $\mathrm{LA}$, Izzo JL et al. The seventh report of the Joint National Committee on Prevention, Detection, Evaluation and

\section{Acknowledgement}

The authors are grateful to Rev. Sister Stella Maris Okoroha of St Damian's hospital, Okporo for permission for the study.

Treatment of high blood pressure: The JNC VII report. JAMA 2003; 289(19):2560-2572.

14. . Araoye MO. Sample size determination. Research Methodology with Statistics for Health and Social Sciences, Ilorin, Nathadex Publishers, 2004; 115-121.

15. Omoigderale Al, Airauhi LU. Aspects of the epidemiology of intestinal parasitoses(IP) in children: knowledge, practices and perceptions of mothers. Nigerian Journal of Clinical Practice, 2006; 9(2): 109-113.

16. Onwubere B, Kadiri S. Guidelines for the management of hypertension in Nigeria. Nigerian Hypertension Society. Enugu, Ezu Books Limited 2005; 1-4.

17. WHO. Definition, diagnosis and classification of diabetes mellitus and its complications. Report of WHO consultation: Geneva, WHO, 1999.

18. Executive summary of the third report of The National Cholesterol Education Programme(NCEP) Expert Panel on Detection, Evaluation and Treatment of high blood cholesterol in adults(Adult Treatment Panel III. JAMA 2001; 285: 2486-2497.

19. Puepet FH, Zoakah Al, Chuwak EK. Prevalence of overweight and obesity among urban Nigerian adults in Jos. Highland Med Res Journ 2002; 1: 13-16.

20. Okesina AB, Oparinde DP, Akindoyin KA,Erasmus RT. Prevalence of some risk factors of coronary heart disease in a rural Nigeria population. EastAfr Med J 1999; 76(4): 212-216.

21. Siminnialayi IM, Emem-Chioma PC, Dapper DV. The prevalence of obesity as indicated by BMl and waist circumference among Nigerian adult attending Family Medicine clinics as outpatients in Rivers state. Niger J Med 2008; 17(3):340-345.

22. Sobngwi E, Mbanya JCN, Unwin NC. Physical activity and its relationship with obesity, hypertension and diabetes in urban and rural Cameroon. International Journal of Obesity. 2003; 26: 1009-1016.

23. Calle EE, Kaaks R. Overweight, obesity and cancer: epidemiological evidence and proposed mechanisms. Nature Reviews Cancer 2004; 4(8):579-591.

24. Biritwum RB, Gyapong J, Mensah G. The epidemiology of obesity in Ghana. Ghana Medical Journal 2005; 39(3):83-85

25. Rana JS, Li TY, Mason JE. Obesity a greater risk than inactivity in women. Diabetes Care 2007; 30: 53-58.

26. Omuemu VO, Okojie OH, Omuemu CE. Awareness of high 
blood pressure status, treatment and control in a rural community in Edo state. Nigerian Journal of Clinical Practice 2007; 10(3):208-212.

27. Akinkugbe $\mathrm{OO}($ ed.). Non-communicable disease in Nigeria: final report of a national survey. Lagos, Federal Ministry of Health and Social Services 1997;12-90.

28. Unachukwu CN, Agomuoh DI, Alasia DD. Pattern of noncommunicable diseases among medical admissions in Port Harcourt, Nigeria. Nigerian Journal of Clinical Practice 2008;11(1):14-17.

29. Dahiru T, Jibo A, Hassan AA. Prevalence of diabetes in a semi-urban community in Northern Nigeria. Niger $\mathrm{J}$ Med 2008; 17(4): 414-416.

30. Amos AF, McCarty DJ, Zimmet P. The rising global burden of diabetes and its complications: estimates and projections to the year 2010. Diabetes Med 1997; 14(5):1-5.

31. Mokdad AH, Ford ES, Bowman BA, Dietz WH, Vinicor F, Bales VS, Mark JS. Prevalence of obesity, diabetes and obesity-related health risk factors. JAMA2003; 289(1): 76-79.
32. Isezuo SA, Badung SLH, Omotoso ABO. Comparative analysis of lipid profiles among patients with type II diabetes mellitus, hypertension and concurrent type II diabetes mellitus and hypertension: a review of metabolic syndrome. J Natl Med Assoc 2003; 95(5): 328-334.

33. Njeleka MA, Negishi H, Nara Y, Sato T, Tomohiro M, Kuga S. Obesity and lipid profiles in middle-aged men and women in Tanzania. East Afr Med J 2002; 79: 58-64.

34. French SA, Story M, Jeffery RW. Environmental influences on eating and physical activity. Am Rev Public Health 2001; 22:309-335.

35. Galuska DA, Will JC, Serdula MK, Ford ES. Are healthcare providers advising obese patients to lose weight? JAMA 1999; 282:1576-1578.

36. Willet WC. Nutritional Epidemiology. New York, Oxford University Press 1998:244-273. 